University of Nebraska - Lincoln

DigitalCommons@University of Nebraska - Lincoln

2-22-1996

\title{
Ultraviolet and electron radiation induced fragmentation of adsorbed ferrocene
}

Dulip Welipitiya

University of Nebraska-Lincoln

A. Green

University of Nebraska-Lincoln

J.P. Woods

University of Nebraska-Lincoln

Peter A. Dowben

University of Nebraska-Lincoln, pdowben@unl.edu

Brian W. Robertson

University of Nebraska-Lincoln, brobertson1@unl.edu

See next page for additional authors

Follow this and additional works at: https://digitalcommons.unl.edu/physicsdowben

Part of the Physics Commons

Welipitiya, Dulip; Green, A.; Woods, J.P.; Dowben, Peter A.; Robertson, Brian W.; Byun, Dongjin; and Zhang, Jiandi, "Ultraviolet and electron radiation induced fragmentation of adsorbed ferrocene" (1996). Peter Dowben Publications. 47.

https://digitalcommons.unl.edu/physicsdowben/47

This Article is brought to you for free and open access by the Research Papers in Physics and Astronomy at DigitalCommons@University of Nebraska - Lincoln. It has been accepted for inclusion in Peter Dowben Publications by an authorized administrator of DigitalCommons@University of Nebraska - Lincoln. 


\section{Authors}

Dulip Welipitiya, A. Green, J.P. Woods, Peter A. Dowben, Brian W. Robertson, Dongjin Byun, and Jiandi Zhang 


\title{
Ultraviolet and electron radiation induced fragmentation of adsorbed ferrocene
}

\author{
Dulip Welipitiya, A. Green, J. P. Woods, ${ }^{\text {a) }}$ and P. A. Dowben ${ }^{\text {b) }}$ \\ Department of Physics and the Center for Materials Research and Analysis, Behlen Laboratory for Physics, \\ University of Nebraska, Lincoln, Nebraska 68588-0111 \\ Brian W. Robertson and Dongjin Byun ${ }^{\mathrm{c}}$ \\ Department of Mechanical Engineering and the Center for Materials Research and Analysis, \\ University of Nebraska, Lincoln, Nebraska 68588-0111 \\ Jiandi Zhang \\ Solid State Division, Oak Ridge National Laboratory, Oak Ridge, Tennessee 37831-6030
}

(Received 13 December 1995; accepted for publication 22 February 1996)

From thermal desorption spectroscopy we find that ferrocene, $\mathrm{Fe}\left(\mathrm{C}_{5} \mathrm{H}_{5}\right)_{2}$, adsorbs and desorbs associatively on $\mathrm{Ag}(100)$. Photoemission results indicate that the initially adsorbed surface species closely resembles that of molecular ferrocene. The shift in photoemission binding energies relative to the gas phase is largely independent of the molecular orbital. We find that ultraviolet light does lead to partial fragmentation of the ferrocene and that the molecular fragments are much more strongly bound to the surface than the associatively adsorbed ferrocene. Since fragmentation occurs only in the presence of incident radiation, selective area deposition from this class of molecules is possible. Using a focused electron beam in a scanning transmission electron microscope, we show that selective area deposition of features with resolution of a few hundred angstroms is readily achieved. (C) 1996 American Institute of Physics. [S0021-8979(96)03911-4]

\section{INTRODUCTION}

To obtain single step radiation assisted (or radiation induced) selective area deposition of iron requires that the source molecule for radiation-induced chemical vapor adsorb and desorb from the surface molecularly in the absence of incident radiation. ${ }^{1}$ Deposition is then restricted only to the region of incident radiation. In this deposition process, radiation (in the form of light, ions, $\mathrm{x}$ rays or electrons) promotes the decomposition of suitable source molecules, usually an organometallic, supplied as a vapor to the substrate surface. Despite great advances in the application of near field optical probes and optical interference techniques, the minimum feature size which may be deposited is still related to the wavelength of the radiation. Thus radiation of shorter wavelengths offer possible routes to better feature resolution.

Synchrotron radiation inducement of surface chemical reactions has become an area of increasing interest. ${ }^{2}$ Ferrocene, $\mathrm{Fe}\left(\mathrm{C}_{5} \mathrm{H}_{5}\right)_{2}$, has been one of those molecules that has been investigated for possible fragmentation following exposure to synchrotron radiation. ${ }^{3}$ For molecular ferrocene adsorption on $\mathrm{Si}(111) 2 \times 1$ surfaces, exposure to unmonochromatized synchrotron light apparently only led to the partial desorption of the adsorbed species and molecular fragmentation was not observed. ${ }^{3}$ This result is somewhat surprising in view of the numerous reports of laser photolytic decomposition of ferrocene leading to the deposition of iron films. ${ }^{4-6}$

The surface photochemistry of ferrocene is, perhaps, better investigated on other surfaces than silicon. Iron deposited

\footnotetext{
${ }^{a)}$ Present address: Phillips Lighting Co., 7265 Route 54, Bath, NY 148109523.

${ }^{b)}$ Electronic mail: pdowben@unlinfo.unl.edu

${ }^{c}$ Present address: Korea Institute of Science and Technology, Division of Metals, P.O. Box 131, Cheongryang, Seoul 130-650, Korea.
}

on $\mathrm{Si}(111)$ can form a silicide, ${ }^{7-12}$ and if there is dissolution of iron into the bulk of silicon, it may be difficult to detect the iron by photoemission. A number of ferrocene-silicon organometallic complexes have now been identified ${ }^{13}$ suggesting that the surface chemistry of ferrocene on $\mathrm{Si}(111)$ may be very complex. For these reasons we have combined thermal desorption spectroscopy with photoemission to investigate the adsorption and desorption of ferrocene on $\operatorname{Ag}(100)$.

With $\mathrm{x}$ rays, much of the dissociation initiated by the $\mathrm{x}$ ray source appears to be the result of the secondary electrons, not the incident photons. ${ }^{14}$ This is because the cross section for photons of very high energy is low relative to the electron cross section and because the electron flux generated by high-energy photons is quite large. This makes electrons in scanning tunneling, projection or focused beam instruments a much more attractive alternative because the radiation can be more precisely directed. Focused electron beams have been employed to induce materials deposition from the iron carbonyl $\left(\mathrm{Fe}(\mathrm{Co})_{5}\right)($ Ref. 15) and more recently, direct writing of features on $\mathrm{Si}(111)$ using ferrocene has been achieved using a scanning tunneling microscope. ${ }^{16} \mathrm{We}$ show that material deposition from ferrocene is possible, with high resolution, in a high vacuum field emission scanning transmission microscope (STEM).

\section{EXPERIMENTAL}

The surface experiments were performed in two UHV chambers, both with base pressures of $5 \times 10^{-10}$ Torr. The photoemission was done in a system equipped with a 117 $\mathrm{mm}$ radius $90^{\circ}$ sector electron energy analyzer described elsewhere. ${ }^{17}$ These experiments were undertaken at the Synchrotron Radiation Center in Stoughton, Wisconsin. The 
photon energy, throughout this work, was $50 \mathrm{eV}$, unless otherwise stated. The light incidence angle was $55^{\circ}$ while the photoelectrons were collected $12^{\circ}$ off the surface normal. The thermal desorption studies were undertaken with a quadrupole mass spectrometer (Dycor) operated in the pulse counting mode and with the temperature measured by a calibrated chromel-alumel thermocouple as has been described elsewhere. ${ }^{18}$

The $\mathrm{Ag}(100)$ crystal was cleaned by repeated $\mathrm{Ar}^{+}$ion bombardment and annealing treatments. ${ }^{18}$ The crystal was mounted in both chambers on a liquid nitrogen cold stage and could be cooled to $130 \mathrm{~K}$. Ferrocene could be sublimed from the solid and was admitted to the chamber through a standard leak valve.

A Vacuum Generators Microscopes model HB5 scanning transmission electron microscope (STEM) was modified to allow controlled introduction of suitable organometallic molecules to the sample substrate surface. A quadrupole mass spectrometer was employed to monitor the gaseous decomposition products during deposition. To promote adsorption of molecular ferrocene and suppress surface diffusion, the substrate temperature was maintained below $150 \mathrm{~K}$ throughout deposition. The supply of the source compound was adjusted with a standard leak valve so that the estimated vapor pressure in the vicinity of the sample was increased to nearly $10^{-7}$ Torr.

Initial deposition studies were undertaken on films of carbon (10 nm thick) or $\mathrm{SiO}$ (about $100 \mathrm{~nm}$ thick) supported over the openings in 200 mesh $3 \mathrm{~mm}$ copper grids. These substrates should be far more chemically inert than the $\operatorname{Ag}(100)$ substrate used to determine the surface chemistry of ferrocene. In this way depositions could be performed with electron energies from 5 to $100 \mathrm{keV}$ and with electron beam diameters in the range from under $1 \mathrm{~nm}$ to more than $10 \mu \mathrm{m}$. The field emission source and optical system are well suited to stable focusing and scanning of the electron beam under electronic control. Also important, the morphology, structure, and other properties of the deposits can be examined in situ with lateral spatial resolution down to about 1 or $2 \mathrm{~nm}$ since the substrates are so thin.

\section{THE ENERGETICS OF MOLECULAR DESORPTION}

We observed the thermal desorption of both iron (mass 56), as seen in Fig. 1 and cyclopentadiene, $\left(\mathrm{C}_{5} \mathrm{H}_{5}\right)$ (mass 65), following the adsorption of ferrocene at $130 \mathrm{~K}$. The thermal desorption peak occurred at a temperature of about $250 \mathrm{~K}$ for both mass fragments. The presence of both iron and cyclopentadienyl ligand desorption at the same temperature indicated that the desorbing species is molecular and that ferrocene desorbs largely intact, i.e., associatively or molecularly.

The relative surface coverage, estimated from the integrated thermal desorption intensities, increases linearly with exposure, as seen in Fig. 1. This strongly suggests that, if ferrocene condenses on $\operatorname{Ag}(100)$, then the molecular desorption process seems to be largely independent of coverage. The desorption temperature is rather low for a strongly chemisorbed species and suggests that adsorption leads to weak chemisorption, again indicative of molecular adsorp-

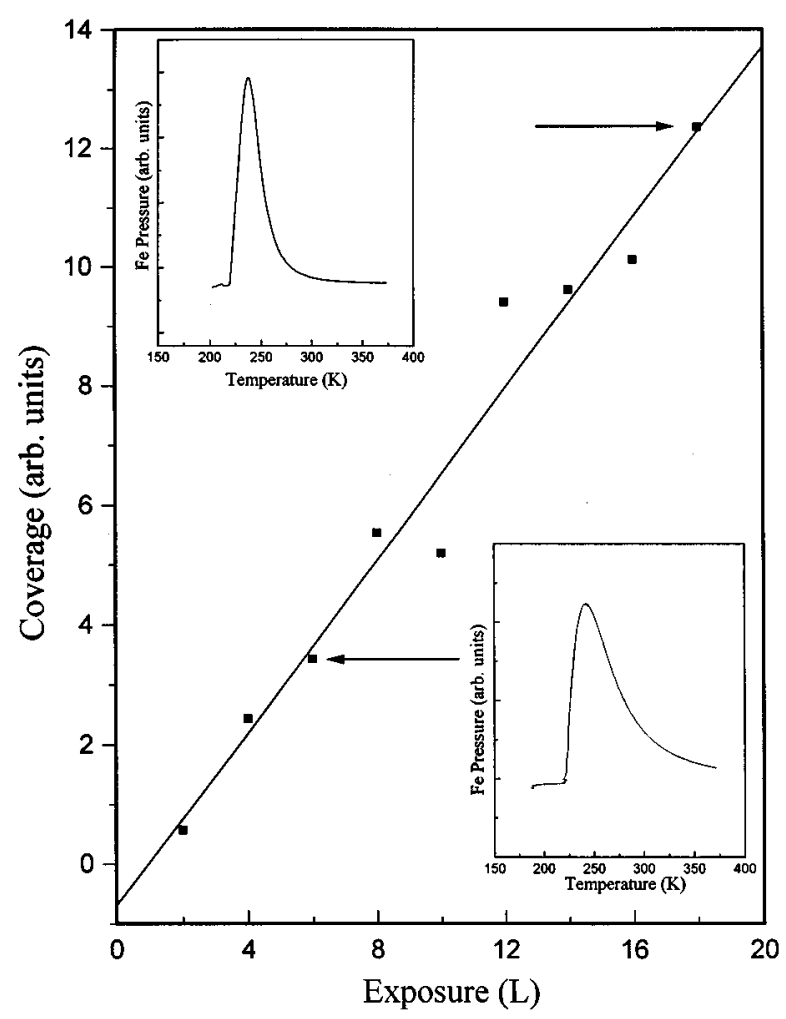

FIG. 1. The relative surface coverage of ferrocene as a function of exposure. This adsorption curves is estimated from the integral of the thermal desorption spectra following adsorption of ferrocene on $\operatorname{Ag}(100)$ at $130 \mathrm{~K}$. The insets show the thermal desorption spectra of iron (mass 56) for large and small exposures, indicating that the desorption of ferrocene is molecular.

tion and desorption. Assuming first-order desorption kinetics and applying the analysis of Chan, Aris, and Weinberg, ${ }^{19}$ we estimate that the desorption energy to be about 1.0 to 0.5 eV/molecule as indicated by Fig. 2 .

The dependence of the apparent heat of desorption in Fig. 2, upon the thermal desorption heating rate, has been observed elsewhere. ${ }^{18,20}$ The more detailed discussion of the dependence of the heat of desorption on thermal desorption heating rates and ferrocene coverage is reserved for a later paper. ${ }^{21}$ It is clear that ferrocene condenses on the $150 \mathrm{~K}$ substrates, temperatures used in the deposition studies described later, yet desorption of the molecular species readily occurs. This shows that both adsorption and desorption behaviors of ferrocene on $\operatorname{Ag}(100)$ or more inert surfaces are compatible with selective area deposition.

\section{IDENTIFICATION OF THE SURFACE SPECIES}

Upon adsorption of ferrocene on $\operatorname{Ag}(100)$ at $130 \mathrm{~K}$, there is suppression of the $\mathrm{Ag} 4 d$ bands and an increase of photoemission features at approximately 4.6, 7.3, 9.3, 11.9, 14.1, and $18 \mathrm{eV}$ as seen in Fig. 3, and summarized in Table I. From theory ${ }^{22-28}$ and gas phase photoemission and ionization potential studies, ${ }^{29-33}$ we can assign these photoemission features of the adsorbed species. The ferrocene $4 e_{2 g}$ and $8 a_{1 g}$ molecular orbitals induce the $4.6 \mathrm{eV}$ feature. The $6 e_{1 u}$ and $4 e_{1 g}$ molecular orbitals result in the $7.3 \mathrm{eV}$ feature. The $6 a_{2 u}$ contributes heavily to the feature at $9.3 \mathrm{eV}$. The 11.9 


\section{$E_{d}$ vs. Exposure}

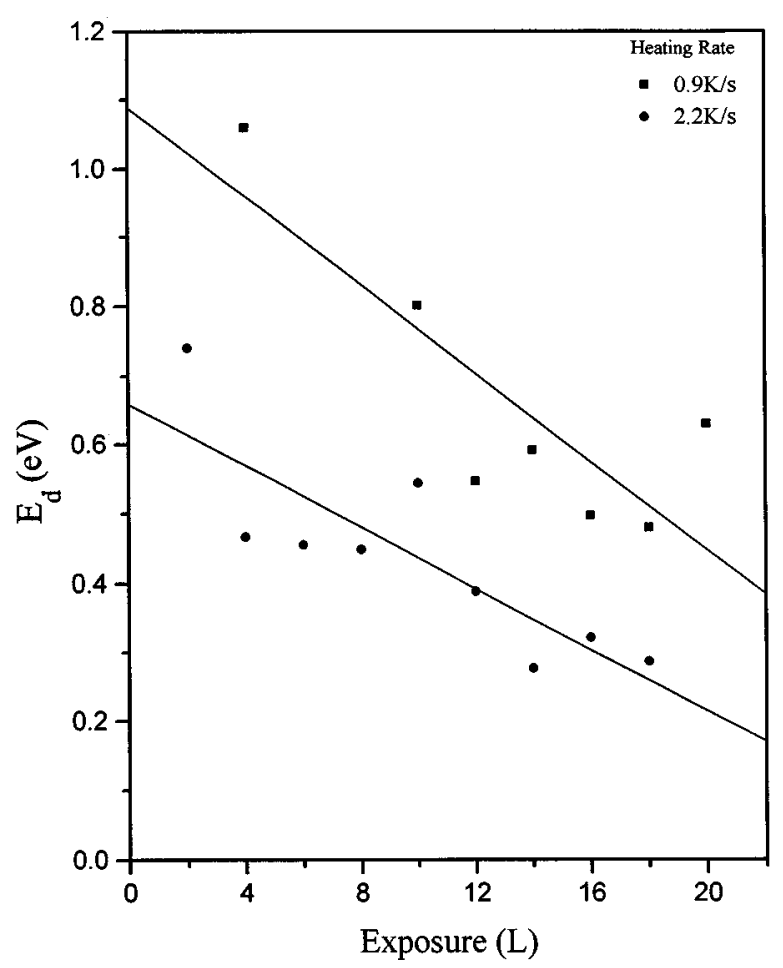

FIG. 2. The heat of desorption as a function of relative surface coverage (exposure) estimated using the method of Chan, Aris, and Weinberg (see Ref. 19). The results are seen to depend upon the heating rate for desorption.

$\mathrm{eV}$ feature is a result of a combination of molecular orbitals $\left(3 e_{2 u}, 3 e_{2 g}, 3 e_{1 g}, 5 e_{1 u}\right.$, and $\left.7 a_{2 g}\right)$ as is the $14.1 \mathrm{eV}$ feature $\left(5 a_{2 u}, 6 a_{1 g}, 2 e_{2 u}\right.$, and $\left.2 e_{1 g}\right)$. These binding energies are referenced to the $\operatorname{Ag}(100)$ Fermi energy and are, therefore,

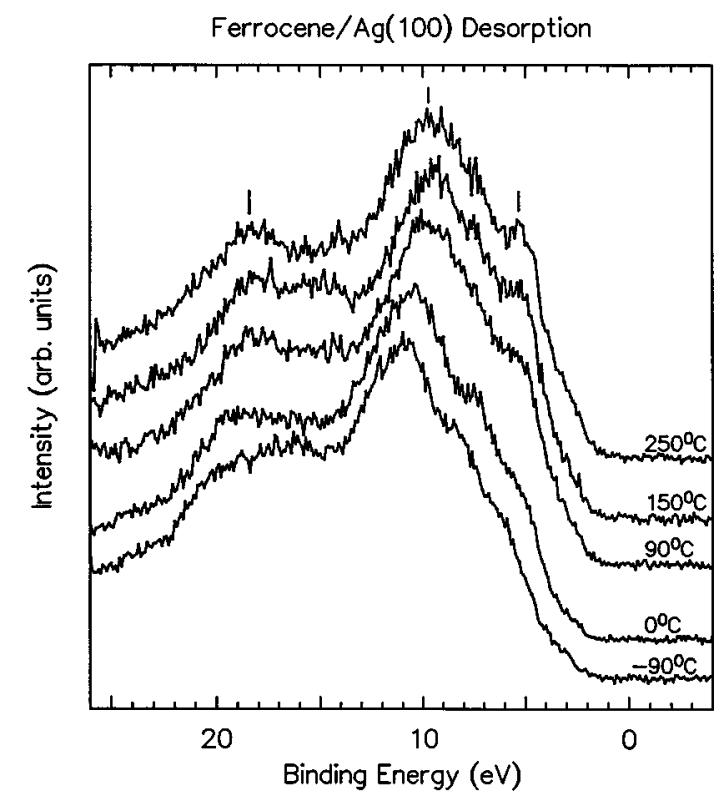

FIG. 3. The photoemission spectra, with temperature, of a film of ferroceneadsorbed $\operatorname{Ag}(100)$ at $130 \mathrm{~K}$. The photon energy is $50 \mathrm{eV}$. The ferrocene exposure was $240 \mathrm{~L}\left(1 \mathrm{~L}=1 \times 10^{-6}\right.$ Torr s).
TABLE I. The molecular orbital binding energies for ferrocene. The binding energies for theory and gas phase experimental measurements are relative to the vacuum level while those for the condensed phase report the binding energies relative to the $\operatorname{Ag}(100)$ Fermi level (this work).

\begin{tabular}{|c|c|c|c|}
\hline Molecular orbitals & Theory $(\mathrm{eV})$ & Gas phase $(\mathrm{eV})$ & $\begin{array}{c}\text { Condensed phase } \\
(\mathrm{eV})\end{array}$ \\
\hline $4 e_{2 g}$ & $\begin{array}{l}5.69^{22} \\
8.3^{23} \\
8.5^{24} \\
6.6^{25} \\
6.7^{26} \\
6.7^{28}\end{array}$ & $\begin{array}{l}6.88^{29} \\
6.85^{30} \\
6.9^{31} \\
6.86^{32} \\
6.86^{33}\end{array}$ & 4.6 \\
\hline $8 a_{1 g}$ & $\begin{array}{c}7.46^{22} \\
10.1^{23} \\
7.9^{24} \\
6.45^{25} \\
6.7^{26} \\
7.6^{27} \\
6.6^{28}\end{array}$ & $\begin{array}{l}7.23^{29} \\
7.21^{30} \\
7.23^{31} \\
7.21^{33}\end{array}$ & $\begin{array}{l}\text { not resolved from } \\
4 e_{2 g}\end{array}$ \\
\hline $6 e_{1 u}$ & $\begin{array}{c}8.85^{22} \\
11.1^{23} \\
9.3^{24} \\
8.53^{25} \\
8.6^{26} \\
12.6^{27} \\
8.6^{28}\end{array}$ & $\begin{array}{l}8.72^{29} \\
8.72^{30} \\
8.72^{31} \\
8.77^{33}\end{array}$ & 7.3 \\
\hline $4 e_{1 g}$ & $\begin{array}{c}8.79^{22} \\
11.2^{23} \\
9.7^{24} \\
7.96^{25} \\
8.1^{26} \\
14.58^{27} \\
7.2^{28}\end{array}$ & $\begin{array}{l}9.38^{29} \\
9.17^{30} \\
9.38^{31} \\
9.28^{33}\end{array}$ & $\begin{array}{l}\text { not resolved from } \\
6 e_{1 u}\end{array}$ \\
\hline $6 a_{2 u}$ & $\begin{array}{l}13.03^{22} \\
15.5^{23} \\
11.7^{24}\end{array}$ & $\begin{array}{l}12.3^{29} \\
12.2^{31} \\
12.2^{33}\end{array}$ & 9.3 \\
\hline $\begin{array}{c}3 e_{2 u}, 3 e_{2 g}, \\
3 e_{1 g}, 5 e_{1 u} \text {, and } \\
7 a_{2 g} \\
5 a_{2 u}, 6 a_{1 g} \text {, } \\
2 e_{2 u}, \text { and } 2 e_{1 g}\end{array}$ & $\begin{array}{l}13.6^{22} \\
11.6^{24}\end{array}$ & $\begin{array}{l}13.0 \text { and } 13.46^{29} \\
13.6^{31} \\
13.3^{33} \\
16.5^{29} \\
16.4^{31} \\
16.6^{33} \\
19.5^{33}\end{array}$ & 11.9 \\
\hline
\end{tabular}

quite different from those observed by Zanoni and coworkers for adsorbed ferrocene. ${ }^{3}$

Since we can identify the photoemission features induced by ferrocene adsorption at $130 \mathrm{~K}$ and attribute these features to the molecular orbitals of molecularly adsorbed ferrocene, we can study the desorption of the molecular species from photoemission. A sequence of spectra from a condensed layer of ferrocene on $\operatorname{Ag}(100)$ is shown in Fig. 3 for increasing annealing temperatures. As is evident from Fig. 3, the $\operatorname{Ag}(100) 4 d$ bands are not recovered in the photoemission spectra even after annealing the substrate to above $250{ }^{\circ} \mathrm{C}$. Thus, it appears from photoemission that the thermal desorption occurs at a much higher temperature than is observed in thermal desorption spectroscopy.

The photoemission and thermal desorption results can be reconciled if the ultraviolet light leads to dissociation, as has been observed for other molecular adsorbates ${ }^{2,34}$ and gaseous substituted ferrocenes. ${ }^{35}$ Even the partial dissociation of fer- 
Photolysis of Ferrocene on $\mathrm{Ag}(100)$

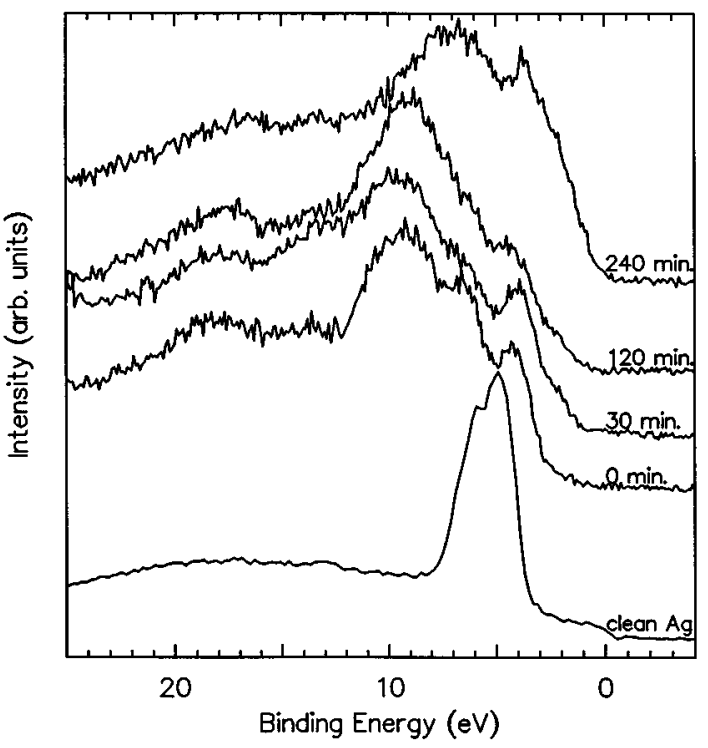

FIG. 4. The change in the photoemission spectra with continued exposure to ultraviolet light of an adsorbed film of ferrocene on $\operatorname{Ag}(100)$ at $130 \mathrm{~K}$. The ferrocene exposure was $240 \mathrm{~L}$. The photoemission spectrum of clean $\mathrm{Ag}(100)$ is shown for reference.

rocene, such as the loss of hydrogen, is very likely to increase the heat of desorption and hence the desorption temperature. The loss of hydrogen or ligand to metal cleavage would leave the molecular orbitals of the cyclopentadiene largely intact. ${ }^{36}$

\section{RADIATION-INDUCED DECOMPOSITION}

Since it has been suggested that ferrocene is such a stable molecule that desorption is favored over decomposition, ${ }^{3}$ it is essential to establish that radiationinduced decomposition can indeed occur. To test if the synchrotron radiation $(50 \mathrm{eV})$ leads to fragmentation of the molecularly adsorbed ferrocene, we investigated the influence of long UV (50 eV photon energy) exposures to a adsorbed ferrocene film on $\operatorname{Ag}(100)$, as shown in Fig. 4. As seen in Fig. 4, long duration exposure of an adsorbed ferrocene film to $50 \mathrm{eV}$ light results in a diminution of the photoemission features attributable to the molecular orbitals of ferrocene. There is, however, little increase in the $\operatorname{Ag}(100)$ substrate $4 d$ features. This indicates that fragmentation without desorption occurs. The lack of distinct photoemission features suggests that the resulting film is a heterogeneous mixture of adsorbate species, perhaps dominated by cyclopentadienyl species bonded to both iron and the $\operatorname{Ag}(100)$ substate. The photoemission spectra are certainly consistent with adsorbed cyclopentadienyl species. ${ }^{36}$

This is a very different conclusion than the one put forward by Zanoni and co-workers. ${ }^{3}$ We cannot, on the data presented here, comment on the nature of the light-induced fragmented surface species. Nonetheless, these results are consistent with the photolysis of ferrocene reported previously. It may be that silicon substrates are even more reactive than is the case for $\operatorname{Ag}(100)$, but given the large number

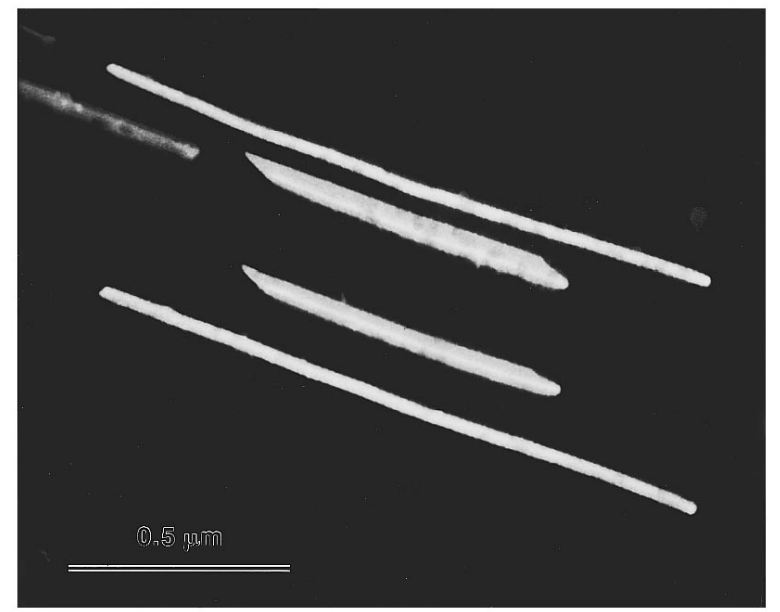

FIG. 5. Scanning transmission electron micrographs of electron beam written deposits containing iron. The bar to the right indicates $200 \mathrm{~nm}$ length scale. The primary energy is $100 \mathrm{keV}$.

of ferrocene-silicon complexes possible, ${ }^{13}$ this could stabilize the adsorbed ferrocene on silicon against decomposition or result in a surface populated by a heterogeneous mixture of ferrocene species, more heterogeneous than is the case on $\mathrm{Ag}(100)$. This would make it very difficult to observed lightinduced decomposition of ferrocene on silicon in photoemission.

\section{SELECTIVE AREA DEPOSITION}

For the initial depositions in the STEM, using single step electron beam deposition, the pattern traced by the electron beam was chosen by selecting a 5 or $10 \mathrm{~ms}$ line scan repetition rate and a $20 \mathrm{~ms}$ frame scan repetition rate from an analog scan generator which controlled the magnetic deflection of the focused electron beam. This results in a scanning of four or two lines on the substrate, respectively. The electron beam current was approximately $0.1 \mathrm{nA}$ and the scanning was maintained for 30 to $180 \mathrm{~s}$, with the electron energies being $100 \mathrm{keV}$.

Bright field and annular dark field STEM micrographs were quite similar for the deposits on both carbon and silicon monoxide substrates. The annular dark field image in Fig. 5 shows the deposits on $\mathrm{SiO}$. It is clear from this image that the deposits are well defined and that the deposits are located only close to the electron beam scanned lines. Stereo pairs of images obtained with tilted substrates reveal that the deposits can exceed $300 \mathrm{~nm}$ in thickness for a $30 \mathrm{~s}$ deposition. The remainder of the substrate is almost entirely free of deposited material. The STEM x-ray microanalysis (EDX) results from the deposits and from the bare substrate confirm that the presence of iron is localized to the scanned lines.

Based upon the deposit dimensions and the electron beam conditions, it is estimated that the deposition efficiency is about $10^{6} \mathrm{~nm}^{3} \mathrm{~s}^{-1} \mathrm{nA}^{-1}$ with electrons of $100 \mathrm{keV}$ energy. For a 1-s exposure by a beam delivering $1 \mathrm{nA}$, this corresponds to deposition of a $1 \mu \mathrm{m}^{2}$ deposit $1 \mathrm{~nm}$ thick or to a cumulative length of $10 \mu \mathrm{m}$ for deposited lines of a $10 \mathrm{~nm}$ square cross section. With optimization of the deposited con- 
ditions and source compound, we estimate that the deposition efficiency, and so the deposition rate, might be increased by a factor of about 100 . If a projection lithographic arrangement is employed with a much greater beam current, a further substantial increase in deposition rate is expected without a significant loss of feature resolution.

\section{CONCLUSION}

In summary, we find that molecular ferrocene adsorbed on $\operatorname{Ag}(100)$ is very weakly adsorbed, desorbing at $250 \mathrm{~K}$. Synchrotron light in the ultraviolet does lead to the partial dissociation of ferrocene adsorbed on the surface. These fragment species are far more strongly chemisorbed on the surface than molecularly adsorbed ferrocene. We have demonstrated electron-beam-induced organometallic chemical vapor deposition (OMCVD) in a single step process for the deposition of iron-containing features with ferrocene as the source molecule.

\section{ACKNOWLEDGMENTS}

This work was supported by the U.S. Department of Energy through grant DE-FG02-95ER12177.AOOO, the Division of Materials Sciences, U.S. Department of Energy, under contract DE-AC05-84OR21400 with Lockeed Martin Energy Systems, Inc., and by the National Science Foundation under grant OSR-92-55225. Portions of this work were carried out at the Synchrotron Radiation Center in Stoughton, Wisconsin. SRC is supported by the NSF.

${ }^{1}$ N. M. Boag and P. A. Dowben, "Designing Organometallics for Vapor Phase Metallization of Plastics," Metallized Plastics 4: Fundamental and Applied Aspects, edited by K. L. Mittal (Plenum, New York, 1996).

${ }^{2}$ R. A. Rosenberg, S. P. Frigo, and J. K. Simons, Appl. Surf. Sci. 79/80, 47 (1994).

${ }^{3}$ R. Zanoni, M. N. Piancastelli, M. Marsi, and G. Margaritondo, J. Electron Spectrosc. Rel. Phenom. 57, 199 (1991).

${ }^{4}$ J. V. Armstrong, A. A. Burk Jr., J. M. D. Coey, and K. Moorjani, Appl. Phys. Lett. 50, 1231 (1987).

${ }^{5}$ G. T. Stauf, D. C. Driscoll, P. A. Dowben, S. Barfuss, and M. Grade, Thin Solid Films 153, 421 (1987).

${ }^{6}$ G. T. Stauf and P. A. Dowben, Thin Solid Films 156, L31 (1988).

${ }^{7}$ O. P. Karpenko, C. H. Olk, S. M. Yalisove, J. F. Mansfield, and G. L. Doll, J. Appl. Phys. 76, 2202 (1994).

${ }^{8}$ J. Chevrier, V. Le Thanh, S. Nitsche, and J. Derrien, Appl. Surf. Sci. 56-58, 438 (1992).

${ }^{9}$ H. Moritz, B. Rosen, S. Popovic, A. Rizzi, and H. Luth, J. Vac. Sci. Technol. B 10, 1704 (1992).

${ }^{10}$ D. Gerthsen, K. Rademacher, Ch. Dieker, and S. Mantl, J. Appl. Phys. 71, 3788 (1992).
${ }^{11}$ H. Sirringhaus, N. Onda, E. Muller-Gubler, P. Muller, R. Stalder, and H. von Kanel, Phys. Rev. B 47, 10567 (1993).

${ }^{12}$ M. G. Grimaldi, P. Baeri, C. Spinella, and S. Logamarsino, Appl. Phys. Lett. 60, 1132 (1992)

${ }^{13}$ M. Herberhold, Angew. Chem. Int. Ed. Engl. 34, 1837 (1995).

${ }^{14}$ F. Keith Perkins, R. A. Rosenberg, S. Lee, and P. A. Dowben, J. Appl. Phys. 69, 4103 (1991); F. Keith Perkins, M. Onellion, S. Lee, Dongqi Li, J. Mazurowski, and P. A. Dowben, Appl. Phys. A 54, 442 (1992).

${ }^{15}$ R. R. Kunz, T. E. Allen, and T. M. Mayer, J. Vac. Sci. Technol. B 5, 1427 (1987); R. R. Kunz and T. M. Mayer, Appl. Phys. Lett. 50, 962 (1987); J. S. Foord and R. B. Jackman, Chem. Phys. Lett. 112, 190 (1984).

${ }^{16}$ F. Thibaudau, T. P. Roge, J. R. Roche, Ph. Mathiez, Ph. Dumas, and F. Salvan, Microsc. Microanal. Microstructuct. 4, 419 (1993); F. Thibaudau, J. R. Rouche, and F. Salvan, Appl. Phys. Lett. 64, 523 (1994).

${ }^{17}$ J. P. Woods, B. M. Patterson, A. S. Fernando, S. S. Jaswal, D. Welipitiya, and D. J. Sellmyer, Phys. Rev. B 51, 1064 (1995).

${ }^{18}$ Y. J. Kime, Jiandi Zhang, and P. A. Dowben, Surf. Sci. 268, 98 (1992).

${ }^{19}$ C.-M Chan, R. Aris, and W. H. Weinberg, Appl. Surf. Sci. 1, 360 (1978).

${ }^{20}$ S. Varma and P. A. Dowben, J. Vac. Sci. Technol. A 8, 2605 (1990).

${ }^{21}$ Dulip Welipitiya, P. A. Dowben, Jiandi Zhang, W. W. Pai, and J. F. Wendelken (unpublished).

${ }^{22}$ P. S. Bagus, U. I. Waldren, and J. Almlof, J. Chem. Phys. 64, 2324 (1976).

${ }^{23}$ M.-M. Coutiere, J. Demuynck, and A. Veillard, Theor. Chim. Acta 27, 281 (1972).

${ }^{24}$ N. Rösch and K. H. Johnson, Chem. Phys. Lett. 24, 179 (1974).

${ }^{25}$ N. Rösch and H. Jörg, J. Chem. Phys. 84, 5967 (1986).

${ }^{26}$ E. J. Baerends and P. Ros. Chem. Phys. Lett. 23, 341 (1973).

${ }^{27}$ R. F. Kirchner, G. H. Loew, and U. T. Mueller-Westerhoff, Theoret. Chim. Acta 41, 1 (1976).

${ }^{28}$ D. R. Armstrong, R. Fortune, and P. G. Perkins, J. Organ. Met. Chem. 111, 197 (1976).

${ }^{29}$ S. Evans, M. L. H. Green, B. Jewitt, G. H. King, and A. F. Orchard, J. Chem. Soc. Faraday Trans. II 356 (1973); S. Evans, M. L. H. Green, B. Jewitt, A. F. Orchard, and and C. F. Pygall, J. Chem. Soc. Faraday Trans. II 68, 1847 (1972).

${ }^{30}$ T. Vondrak, J. Organometallic Chem. 275, 93 (1984).

${ }^{31}$ J. W. Rabalais, L. O. Werme, T. Bergmark, L. Karson, M. Hussain, and K. Siegbahn, J. Chem. Phys. 57, 1185 (1972).

${ }^{32}$ D. C. Driscoll, P. A. Dowben, N. M. Boag, M. Grade, and S. Barfuss, J. Chem. Phys. 85, 4802 (1986).

${ }^{33}$ C. Cauletti, J. C. Green, M. R. Kelly, P. Powell, J. van Tilborg, J. Robbins, and J. Smart, J. Electron Spectrosc. Rel. Phenom. 19, 327 (1980).

${ }^{34}$ P. A. Dowben and M. Grunze, Ber. Bunsenges. Phys. Chem. 85, 728 (1981); D. C. Mancini, S. Varma, J. K. Simons, R. A. Rosenberg, and P. A. Dowben, J. Vac. Sci. Technol. B 8, 1804 (1990); D. Byun, S.-D. Hwang, P. A. Dowben, F. K. Perkins, F. Filips, and N. J. Ianno, Appl. Phys. Lett. 64, 1968 (1994); D. Byun, S.-D. Hwang, J. Zhang, F. K. Perkins, G. Vidali, and P. A. Dowben, Jpn. J. Appl. Phys. Lett. 34, L941 (1995).

${ }^{35}$ S. Barfuss, K.-H. Emrich, W. Hirschwald, P. A. Dowben, and N. M. Boag, J. Organometallic Chem. 391, 113 (1990).

${ }^{36}$ F. P. Netzer, Chem. Phys. Lett. 146, 566 (1988); F. P. Netzer, A. Goldmann, G. Rosina, and E. Bertel, Surf. Sci. 204, 387 (1988); F. P. Netzer, G. Rosina, E. Bertel, and H. B. Saalfeld, J. Electron Spectrosc. Rel. Phenom. 46, 373 (1988). 